\title{
Prevalence of anorexia nervosa among adolescent girls
} Umarani. $J^{1}$, Amirthraj $A A^{2}$

\begin{abstract}
:
Background: Girls tend to be more concerned about their physical appearance than boys during adolescent period. Adolescent girls are more likely to care for losing weight with the fear of being "fat". Anorexia nervosa (AN), a form of self-starvation, is an eating disorder characterized by a distorted body image that leads to restricted eating and other behavior that prevents a person from gaining weight. It commonly occurs in teenage girls, although boys are also affected, especially in the prepubertal age group. Hence the researcher would like to assess the prevalence of anorexia nervosa among the adolescent nursing students. Objectives: 1. Determine the prevalence of anorexia nervosa among adolescent girls. 2. Find out the association between prevalence and selected demographic variables. Materials and Methods: The study was conducted among 100 B.Sc Nursing 1st year students at selected nursing colleges of Mangalore. The samples were selected by convenience sampling method. After obtaining informed consent and ethical clearance the data was collected by assessing the baseline proforma and Eating Attitude Test. Findings: It was found that $31 \%$ of the adolescent girls were having high risk to anorexia nervosa and $69 \%$ were of no risk, whereas none of them were found consistent with anorexia nervosa. It was noted that all the 31 high risk girls were hostel residents. There was no association found between the risk of anorexia nervosa and the selected demographic variables. Conclusion: Some perceive anorexia as a simple case of vanity taken too far, but rather it is a complex psychological problem. So it is the responsibility of the teachers to create awareness among students by educating about the ill effects of anorexia nervosa which help us to prevent the incidence of anorexia nervosa and lead to healthy adolescents to the society.
\end{abstract}

Key Words: anorexia nervosa; adolescence; prevalence

Bangladesh Journal of Medical Science Vol. 15 No. 03 July'16. Page : 466-470

\section{Introduction:}

Adolescence is derived from Latin word adolescence, meaning "to grow up" is a transitional stage of physical and psychological human development that generally occurs during the period from puberty to legal adulthood, the age of majority ${ }^{1,2}$

Modern day adolescents are exposed to many representations of ideal beauty. The concept of a person being unhappy with their own image or appearance has been defined as "body dissatisfaction". In teenagers, body dissatisfaction is often associated with body mass, low self-esteem, and atypical eating patterns. ${ }^{3}$

Body image is the dynamic perception of one's body- how it looks, feels, and moves. It is shaped by perception, emotions, physical sensations, and is not static, but can change in relation to mood, physical experience, and environment. $50-88 \%$ of adolescent girls feel negatively about their body shape or size. $49 \%$ of teenage girls say they know someone with an eating disorder. ${ }^{4,5}$ Only $33 \%$ of girls say they are at the "right weight for their body", while $58 \%$ want to lose. weight. Just $9 \%$ want to gain weight. ${ }^{6}$ Females are much more likely than males to think their current size is too large $(66 \%$ vs. $21 \%) .^{7}$

Anorexia nervosa is characterized by restricted eating, loss of weight and a fear of putting on

1. J. Umarani, Associate professor, Department of paediatric Nursing, Yenepoya Nursing College, Yenepoya University, Mangalore

2. Dr. Anand A Amirthraj, Additional Professor, Department of Oral and Maxillofacial Surgery, Manipal College of Dental Sciences, Manipal University, Mangalore

Corresponds to: J. Umarani, Yenepoya Nursing College, Yenepoya University, Deralakatte, Mangalore-575018. E-mail: umasrmc1@gmail.com 
weight. $^{8}$ Anorexia nervosa (AN), a form of selfstarvation, is an eating disorder characterized by a distorted body image that leads to restricted eating and other behavior that prevents a person from gaining weight. Anorexia nervosa is sometimes referred to as anorexia. The majority of those affected are females (90 to 95 percent), although those statistics are changing as males are now more frequently affected. Initially identified in upper- and middle-class families, anorexia is now known to be found in all socioeconomic groups and a variety of ethnic and racial groups. ${ }^{9}$

Adolescence is a period of psychosocial change that is often perplexing for both teens and their parents. The rapid physical changes that occur at this time lead adolescents to become preoccupied with their body image. Adolescents may become preoccupied with themselves, uncertain about their appearance, compare their bodies with those of other teens, and become increasingly interested in sexual anatomy and physiology. ${ }^{10}$ Anorexia nervosa is an eating disorder that disproportionately affects adolescents and has its origin, at least partially, in this preoccupation with body image.Anorexia nervosa is an eating disorder characterized by a fierce quest for thinness. The Diagnostic and Statistical Manual of Mental Disorders, fourth edition, defines patients with anorexia nervosa as having an intense fear of gaining weight, putting undue influence on body shape or weight for selfimage, having a body weight which is less than $85 \%$ of the weight that would be predicted, and missing at least three consecutive menstrual periods. ${ }^{11}$ The prevalence of disordered eating attitudes in boys is lower than in girls, however there is evidence that it is gradually increasing. ${ }^{12}$

Anorexia nervosa most commonly occurs in teenage girls, although boys are also affected, especially in the prepubertal age group. The ratio of girls to boys is approximately $10-20: 1 .{ }^{13}$ About $2 \%$ to $3 \%$ of young women have anorexia nervosa or a clinically important variant of the disorder. ${ }^{14}$ There has been a consistent increase in the incidence of anorexia nervosa over the past 10 years. ${ }^{15}$ The variable performance of questionnaires designed to screen for eating disorders, such as the Eating Attitudes Test and the Eating Disorders Inventory, coupled with the difficulty of defining cases and the tendency of patients to hide their illness has made epidemiological studies difficult. ${ }^{16,17,18}$

In a cross-sectional study assessing body image perception and satisfaction in the European Union,
Table.1 Category of EAT-26

\begin{tabular}{|c|c|}
\hline $\begin{array}{l}\text { S. } \\
\text { No. }\end{array}$ & Category of rating scale \\
\hline I. & $\begin{array}{l}\text { Dieting: } \\
\text { 1. Like eating with other people } \\
\text { 2. Find myself preoccupied with food } \\
\text { 3. Have gone on eating binges where I } \\
\text { feel that I may not be able to stop } \\
\text { 4. Particularly avoid foods with a high } \\
\text { carbohydrate content } \\
\text { 5. Feel bloated after meals } \\
\text { 6. Feel that others would comment if I } \\
\text { ate more } \\
\text { 7. Feel extremely guilty after eating } \\
\text { 8. Exercise strenuously to burn off } \\
\text { calories } \\
\text { 9. Weigh myself several times a day } \\
\text { 10. Think about burning my calories } \\
\text { when I exercise } \\
\text { 11. Have regular menstrual periods } \\
\text { 12. Other people think that I am too thin } \\
\text { 13. Take longer than others to eat my } \\
\text { meal }\end{array}$ \\
\hline II. & $\begin{array}{l}\text { Preoccupied with Bulimia and Food: } \\
\text { 1. Become anxious prior to eating } \\
\text { 2. Am terrified about being overweight } \\
\text { 3. Aware of the calorie content of foods } \\
\text { that I eat } \\
\text { 4. Like my clothes to fit tightly } \\
\text { 5. Eat the same foods day after day } \\
\text { 6. Am preoccupied with the thought of } \\
\text { having fat on my body }\end{array}$ \\
\hline III. & $\begin{array}{l}\text { Oral Control: } \\
\text { 1. Prepare foods for others but do not eat } \\
\text { what I cook } \\
\text { 2. Avoid eating when I am hungry } \\
\text { 3. Cut my food in to small pieces } \\
\text { 4. Vomit after I have eaten } \\
\text { 5. Am preoccupied with a desire to be } \\
\text { thinner } \\
\text { 6. Enjoy eating meat } \\
\text { 7. Wake up early in the morning }\end{array}$ \\
\hline
\end{tabular}

it was shown that Greece had the highest percentage of subjects who wished to be considerably lighter $(18 \%)$, whereas Denmark had the lowest $(7 \%) .{ }^{19}$ Dieting is a major risk factor for eating disorders. The prevalence of eating disorders in a culture parallels the prevalence of dieting behavior. ${ }^{14}$ Studies have confirmed that white women in higher socioeconomic classes diet more and are more concerned about their weight than other 
Table.2 Response of the participants for the rating scale $\mathrm{N}=\mathbf{1 0 0}$

\begin{tabular}{|c|c|c|c|c|}
\hline Category of rating scale & Always (\%) & Very Often (\%) & Often (\%) & $\begin{array}{c}\text { Sometimes or } \\
\text { Never (\%) }\end{array}$ \\
\hline Dieting & 20 & 7 & 4 & None \\
\hline Preoccupied with Bulimia and Food & 5 & 7 & 10 & 8 \\
\hline Oral Control & 16 & 6 & 5 & 4 \\
\hline
\end{tabular}

subgroups of women. ${ }^{16}$ Participation in hobbies and occupations, such as modeling and ballet, that promote the ideal of thinness seems to lead to a higher prevalence of eating disorders. ${ }^{13}$

The present study aimed to find the prevalence of anorexia nervossa among adolescent girls in selected nursing colleges of Mangalore.

\section{Materials and Methods:}

Descriptive design was chosen for the study. A total of 100 samples were selected by convenience sampling technique. The study participants were the I Year B.Sc.Nursing female Students of selected Nursing Colleges of Mangalore. Permission obtained from the Research and Institution Ethics Committee as well as from the concerned authority of the selected colleges. Consent for voluntary participation obtained from the study participants.

The study instrument consists of 2 part. Part-I Baseline data which includes age, height, weight, socio economic status, family income, living area and birth order Part-II standardized Self administered 4 point Likert scale- Eating Attitude Test(EAT) developed by Garner and Garfinkel ${ }^{20}$ comprises of 26 statements with the score from 0-3 and a total score of 78. The scale is catogorized into 3 aspects(table.1) such as dieting, Preoccupied with Bulimia and Food, oral control. To complete the EAT-26, participants rate their agreement with statements about weight and food. A total score at or above 20 in the questionnaire indicates abnormal eating behavior. The scores were interpreted as $<20$-No risk, 20-49 -High risk, 50-78 consistent with anorexia.

The self administered standardized rating scale Eating Attitude Test(EAT) by Garner and Garfinkel was given to the participants and it was collected back after 30 minutes. Demographic variables and the response for rating scale were analyzed by frequency, percentage, mean and standard deviations. Association between the prevalence and selected demographic variables were determined by using chi- square test.

Results:

The baseline proforma depicts that all the girls were in the age of 18yrs. In regard to type of family 98 belongs to middle class family, 2 belongs to upper class and none of them were of lower class. Majority (96) of the samples were hostelite, 3were paying guest and only 1 was residing with parents.

Table. 2 shows that majority $(20 \%)$ of the students always do dieting to maintain their body weight and $16 \%$ practiced oral control to avoid weight gain. None of the samples practiced diet control and $8 \%$ of the subjects expressed that sometimes they were preoccupied with Bulimia and food.

It was found (Table.3) that $31 \%$ of the adolescent girls were having high risk to anorexia nervosa and $69 \%$ were of no risk, whereas none of them were found consistent with anorexia nervosa. It was noted that all the 31 high risk girls were hostelite. There was no association found between the risk of anorexia nervosa and the selected demographic variables.

\section{Discussion:}

The result of present study reveales that none of the samples are consistent with anorexia, and only a minimal percentage $(31 \%)$ of the sapmles were

Table.3 Prevalence of Anorexia Nervosa among adolescent girls

\begin{tabular}{|l|c|c|}
\hline S.No. & Risk for Anorexia & Percentage \\
\hline 1. & No risk & 69 \\
\hline 2. & High risk & 31 \\
\hline 3. & $\begin{array}{c}\text { Consistent with } \\
\text { anorexia. }\end{array}$ & NIL \\
\hline
\end{tabular}

of in the category of high risk to anorexia, where as majoriy $(69 \%)$ of the samples were of no risk. This results are in contrast with a study where the Populations of schoolgirls were surveyed in respect of the occurrence of anorexia nervosa. As well as the current school year, previous years (going back variously 3-6 years) were also carefully studied within seven of the schools. Anorexia nervosa was only identified as present or having been present if the diagnosis was unequivocal: for instance, seemingly evident and severe cases which could not be traced were excluded. The 
condition in severe form was found to be relatively common in the independent sector of education, probably implying a social class factor. In all such schools, the prevalence was one severe case in approximately every 200 girls. In those aged 16 and over it amounted to one severe case in about every 100 girls. Overall, these schools encountered one 'new' severe case in every 250 pupils aged 16 years and over. The condition is likely to be even more common than this study allows because of the stringent limits set here on inclusion of cases and the age-bands studied. It is concluded that severe anorexia nervosa is a common condition. ${ }^{21}$

Another study was undertaken to determine incidence and prevalence rates and long-term trends in incidence of anorexia nervosa by identifying all persons residing in the community of Rochester, Minn., during the 50-year period 1935 through 1984 who had the disorder. From a communitybased epidemiologic resource, 13,559 medical records with diagnoses of amenorrhea, starvation, weight loss, anorexia nervosa, or other conditions were screened to identify true cases of anorexia nervosa determined by using standard diagnostic criteria. One hundred eighty-one residents (166 female and 15 male) fulfilled the diagnostic criteria for anorexia nervosa; these were the incidence cases. Due to a quadratic trend in the rates for girls 10-19 years old, the incidence rate among female residents fell from 16.6 per 100,000 person-years in the 1935-1939 period to a low of 7.0 in 19501954 and increased to 26.3 in 1980-1984. The incidence rates for women 20 years old and older and for males remained constant. For females 15-24 years old, there was a linear increase. The overall age-adjusted incidence rate per 100,000 personyears was 14.6 for females and 1.8 for males. The prevalence rate per 100,000 population was 269.9 for females and 22.5 for males ${ }^{22}$.

A study conducted to determine the Prevalence of anorexia nervosa, bulimia nervosa and other eating disorders in adolescent girls in Reus (Spain)]. He performed a cross-sectional observational study in a random sample of adolescent girls aged between 12 and 21 years old. Information was gathered from a structured questionnaire on demographic and anthropometric factors (age, place of birth, education, etc.), clinical examination, clinical interview, DMS-IV diagnostic criteria, and three self-administered tests: EAT-40, BAT and CIMEC.A total of 551 adolescents were analyzed. All the adolescents that met the diagnostic criteria of anorexia nervosa showed alterations in all three tests. ${ }^{23}$

In the present study there was no association found between the risk of anorexia nervosa and the selected demographic variables, whereas another study revealed that the presence of overweight preoccupation and fear of fatness in adolescents is strongly associated with an increased risk of developing clinical eating disorders. ${ }^{24}$ The study was conducted on a smaller number of samples where the results cannot be generalized, which is the limitation of the study.

\section{Acknowledgement:}

The authors are grateful to Garner, D.M.and Garfinkel, P.E for permitting to use the Eating Attitude Test (EAT) Scale and the participants for their valuable support for the study.

\section{Conclusion:}

Anorexia nervosa is a serious problem that affects a significant proportion of the world's adolescent population. Some perceive anorexia as a simple case of vanity taken too far, but rather it is a complex psychological problem. So it is the responsibility of the teachers to create awareness among students by educating about the ill effects of anorexia nervosa which help us to prevent the incidence of anorexia nervosa and lead to healthy adolescents to the society. Conflict of interest: None 


\section{References:}

1. Macmillan Dictionary for Students Macmillan, Pan Ltd. (1981), page 14, 456.

2. "Adolescence". Merriam-Webster.

3. Mäkinen et al,. Body dissatisfaction and body mass in girls and boys transitioning from early to midadolescence: additional role of self-esteem and eating habits. BMC Psychiatry 2012 12:35.

4. EPM Communications. Youth Markets Alert 2000;12:8.

5. Field AE, Cheung L, Wolf AM, Herzog DB, Gortmaker SL, Colditz GA. Exposure to the mass media and weight concerns among girls. Pediatrics 1999;103(3):E36.

6.SmartGirl Speaks. Eating disorder quick poll reports. SmartGirl.org, University of Michigan.

http://www.smartgirl.org/.

7.Rand CS, Resnick JL, Seldman RS. Assessment of socially acceptable body sizes by university students. Obes Res 1997;5(5):425-429ss

8. www.betterhealth.vic.gov.au/bhcv2/...nsf/.../eating disorders_adolescent

9. Www.stanfordchildrens.org/en/topic/ default?id=anorexia-nervosa-in.

10. Neinstein L, Juliani M, Shapiro J. Psychosocial development in normal adolescents. In: Neinstein L, ed. Adolescent health care: a practical guide. Baltimore: Williams and Wilkins; 1996: 42-44.

11. Pryor T. Diagnostic criteria for eating disorders: DSM IV revision. Psychiatr Ann 1995;25: 40-49.

12. Herpertz-Dahlmann, B., Wille, N., Holling, H., Vloet, T. D., \& Ravens-Sieberer, U. (2008). Disordered eating behaviour and attitudes, associated psychopathology and health-related quality of life: Results of the BELLA study. European Child \& Adolescent Psychiatry, 17, 82-91.

13. Pawluck DE, Gorey KM. Secular trends in the incidence of anorexia nervosa: integrative review of populationbased studies. Int J Eat Disord 1998;23: 347-352.
14. Shisslak CM, Crago M, Estes LS. The spectrum of eating disturbances. Int J Eat Disord 1995;18: 209-219.

15. Engles J, Hohnston M, Hunter D, et al. Increasing incidence of anorexia nervosa. Am J Psychiatry 1995;152: 1266-1271.

16. Hsu LKG. Epidemiology of the eating disorders. Psychiatr Clin North Am 1996;19: 681-700.

17. Wakeling A. Epidemiology of anorexia nervosa. Psychiatry Res 1996;62: 3-9.

18. Fichter MD, Elton M, Engle K, et al. Structured interviews for anorexia and bulimia. Int J Eating Disord 1991;10: 571-592.

19. McElhone, S., Kearney, J.M., Giachetti, I., Zunft, H.J. \& Martinez, J.A. (1999) Body image perception in relation to recent weight changes and strategies for weight loss in a nationally representative sample in the European Union. Public Health Nutr 2, 143-151.

20. Garner, D.M. \& Garfinkel, P.E. (1979) The Eating Attitudes Test: an index of the symptoms of anorexia nervosa. Psychol. Med. 9, 273-279.

21. Crisp AH, Palmer RL, Kalucy RS. How common is anorexia nervosa? A prevalence study. Br J Psychiatry. 1976 Jun;128:549-54.

22. Lucas $\mathrm{AR}^{1}$, Beard CM, O'Fallon WM, Kurland LT, 50-year trends in the incidence of anorexia nervosa in Rochester, Minn.: a population-based study. Am J Psychiatry. 1991 Jul;148(7):917-22.

23. Olesti Baiges, M., Pinol Moreso, J. L., Martin Vergara, N., de la Fuente Garcia, M., Riera Sole, A., Bofarull Bosch, J. M., et al. (2008). Prevalence of anorexia nervosa, bulimia nervosa and other eating disorders in adolescent girls in Reus (Spain). Annals of Pediatrics (Barcelona), 68, 18-23.

24. Goldschmidt, A. B., Aspen, V. P., Sinton, M. M., Tanofsky-Kraff, M., \& Wilfley, D. E. (2008). Disordered eating attitudes and behaviors in overweight youth. Obesity (Silver Spring), 16, 257-264. 